\title{
OPERAÇÕES INTERTEXTUAIS NA CATEGORIA TÍTULO NO JORNAL CARIOCA MEIA HORA
}

\author{
Vanda Cardozo de Menezes* \\ Universidade Federal Fluminense \\ Niterói, Rio de Janeiro, Brasil \\ Wagner Alexandre dos Santos Costa* \\ Universidade Federal Rural do Rio de Janeiro \\ Seropédica, Rio de Janeiro, Brasil
}

\begin{abstract}
Resumo: Com o intuito de demonstrar que nos jornais populares a notícia também pode ser perpassada por uma opinião, porém a partir de estratégias não convencionais, neste artigo analisaremos a construção do título "Papa pede pra sair", de notícia publicada no jornal popular carioca Meia Hora, em 12/02/2013. Nossa preocupação se concentra na reflexão de como o estabelecimento de uma relação intertextual, já no título, pode acrescentar sentidos e orientar argumentativamente o texto. Uma de nossas conclusões é que o título seria o espaço reservado pelo jornal para sugerir alguma opinião, em vez de desenvolvê-la de forma longa no decorrer do texto, o que poderia infringir o contrato de comunicação entre jornal e leitor desse segmento. Como aparato teórico, vamos nos pautar na noção de "contrato de comunicação", desenvolvida na Análise do discurso (CHARAUDEAU, 1996; 2001); na caracterização dos "valores-notícia” (AMARAL, 2006); e no processo de "intertextualidade" (BEAUGRANDE; DRESSLER (1981); BAKHTIN (2003); KOCH (2003), entre outros.
\end{abstract}

Palavras-chave: Jornalismo popular. Intertextualidade. Construção de sentidos.

1 INTRODUÇÃO

É comum a afirmação de que a notícia deve constituir um relato imparcial, como é recomendado, por exemplo, no Manual da Redação (Folha de S.Paulo, 2001). Certamente isto constitui menos regra do que aparenta, conforme evidenciam cotidianamente diferentes jornais. Esse fenômeno ocorre porque, simultaneamente à força estabilizadora do gênero, há o ato de realização efetivo do texto, que, nesta dimensão, submete-se a diferentes coerções, devido ao contrato de comunicação não ser sempre o mesmo, não ser idêntico.

A oposição entre jornais de referência e jornais populares (AMARAL, 2006), por exemplo, insere-se nesse contexto, no sentido de que o projeto de dizer no noticiário de

\footnotetext{
* Doutora em Letras Vernáculas pela Universidade Federal do Rio de Janeiro (UFRJ). Professora Associada III no Departamento de Letras da UFF. Email: vcmenezes@terra.com.br.

** Doutor em Estudos da Linguagem pela Universidade Federal Fluminente (UFF). Professor Assistente A1 da Universidade Federal Rural do Rio de Janeiro (UFRRJ). Email: costawas@oi.com.br.
} 
cada tipo de jornal imputa-lhe certas características e adoção de estratégias específicas, como a seleção de fatos segundo valores-notícia distintos e emprego de linguagem projetada num certo perfil de leitor ${ }^{1}$. Inclui-se, também, o tratamento dado ao fato: por um lado, nos jornais de referência, com maior inclinação política e organização argumentativa; por outro, nos jornais populares, atendendo a valores de entretenimento e proximidade e com organização predominantemente narrativa e expositiva.

Neste trabalho, demonstraremos como uma notícia de jornal pode conter opinião e oferecer uma orientação argumentativa ao tema - pela forma como o recorta e pelo estabelecimento de relações intertextuais existentes já no título. Assim, o fulcro de nosso interesse recai sobre essa reflexão e, para tanto, analisaremos a construção do título "Papa pede pra sair", de notícia publicada no jornal popular carioca Meia Hora, em $12 / 02 / 2013$.

Nosso aporte teórico basilar pauta-se na noção de "contrato de comunicação", desenvolvida na Análise do discurso (CHARAUDEAU, 1996; 2001); na caracterização dos "valores-notícia" (AMARAL, 2006); e no processo de "intertextualidade", tal como definido por Beaugrande e Dressler (1981). Adotaremos ainda considerações de Bakthin (2003) e Koch (2003).

Assim, na seção 2, discorreremos sobre o papel dos sujeitos e a produção de sentidos de acordo com a teoria semiolinguística. Na seção 3, trataremos dos principais valores-notícia para o jornalismo popular e, na seção 4, da noção de intertextualidade. Já a seção 5 comporta a análise da produção de sentidos por meio da intertextualidade, tal como produzida no título.

\section{QUADRO SOCIOLINGUAGEIRO}

A Teoria Semiolinguística postula que a construção do sentido leva em conta simultaneamente duas dimensões: uma situacional e outra linguística da significação discursiva, que é construída, segundo Charaudeau (1996, p. 8), sobre uma dupla interrelação, a saber:

a) entre dois espaços de produção de sentido, sendo um externo, outro interno;

b) entre dois espaços enunciativos: de produção (EU) e de interpretação (TU).

Sendo assim, algumas hipóteses norteiam o quadro teórico exposto por Charaudeau (2001, p. 28):

A primeira é a de que $o$ ato de linguagem decorre das instâncias do dizer e do fazer, sendo o fazer a instância situacional onde estão situados os responsáveis deste ato. O dizer, instância discursiva, corresponde ao espaço de produção do qual participam os seres da palavra. Por isso, as realidades do dizer e do fazer desdobram-se em dois circuitos interdependentes: um externo (fazer), outro interno (dizer).

\footnotetext{
${ }^{1}$ Conforme dados extraídos de <www.odiacomercial.com.br/pdf/perfil_leitrores_2012.pdf $>$ (consulta em $28 / 4 / 2012$ ), a maior parte do público leitor, $64 \%$, pertence às classe $\overline{\mathrm{C}}$ e $\mathrm{D}$, e $28 \%$ moram na Baixada Fluminense.
} 
A segunda diz que o ato de linguagem é determinado pelas especificações situacionais. Sendo uma interação, é dotado de intencionalidade, o que implica dizer que a encenação discursiva é uma atividade estratégica.

A terceira vincula o ato de linguagem às práticas e imaginários sociais de dada comunidade, sendo ele o produto da ação de sujeitos psicossociais.

Essa relação contratual não se baseia nos estatutos sociais das pessoas nela implicadas, "depende do 'desafio' construído no e pelo ato de linguagem" (CHARAUDEAU, 2006, p. 30).

A abrangência do ato de linguagem, que se realiza em um duplo espaço de significância, o externo e o interno, determina, conforme Charaudeau (1996, p. 5), dois tipos de sujeitos da linguagem: os parceiros, que são os sujeitos do fazer social, seres reais, chamados de EUc (EU comunicante) e de TUi (TU interpretante); e os protagonistas, que são os sujeitos do dizer, seres hipotéticos, denominados de EUe (EU enunciador) e de TUd (TU destinatário). Ou seja, no circuito interno, encontram-se os seres da palavra (EUe, TUd) e no circuito externo os seres agentes (EUc,TUi).

No processo de produção, o EUe corresponde ao papel discursivo que o EUc (produtor do ato de linguagem) constrói dele mesmo enquanto ser do discurso em cena. Tal papel é idealizado em função das intenções comunicacionais do sujeito situado no plano do fazer.

Em se tratando de uma hipótese, o trabalho realizado pelo EUc pode (ou não) obter o resultado desejado, conforme sua hipótese seja avaliada pelo TUi. Este pode, por exemplo, aceitar a imagem dele feita por aquele. Mas pode, por outro lado, negá-la. Isto porque também faz de si próprio uma imagem discursiva, sendo esta o TUd. Além disso, pode questionar-se sobre o papel do comunicante. É o que ocorre em enunciados como Quem é x para falar assim comigo? Ou seja, o EUc obterá tanto mais êxito, quanto maior for a proximidade entre a hipótese criada por ele sobre o TUd e a referida imagem deste construída pelo TUi.

Assim, os universos de discurso dos sujeitos que ancoram o ato de linguagem não são idênticos, visto que ambos, locutor e interlocutor, constroem para si imagens um do outro que podem não ser reais. Não sendo unidirecional, ele é, portanto, dialógico. $\mathrm{O}$ ato de linguagem corresponde, por isso, a um ato interenunciativo (CHARAUDEAU, 2010a, p. 45) entre quatro sujeitos, e não dois.

Charaudeau pauta este quadro teórico, como foi dito antes, em uma recíproca relação de intencionalidade entre as instâncias externa e interna. Como se trata de um quadro que prevê objetos semiodiscursivos postos em troca, por decorrência (no discurso jornalístico, por exemplo) teremos três instâncias implicadas: as duas primeiras, a de produção e a de recepção; a terceira, o texto. Portanto:

No que tange à máquina midiática, a primeira instância é representada pelo produtor de informação (o organismo de informação e seus atores), a instância de recepção pelo consumidor da informação (diferentes públicos: leitores, ouvintes, telespectadores) e o produto pelo texto midiático (artigo de jornal, boletim radiofônico, telejornal etc.) (CHARAUDEAU, 2010b, p. 24). 
O lugar das instâncias de produção do sentido subdivide-se em dois: é determinado por condições socioeconômicas (espaço externo) reguladas por práticas mais ou menos institucionalizadas (empresariais, por exemplo) com as quais os atores sociais estão comprometidos. Simultaneamente, tais atores devem engajar-se na produção de discursos, que correspondem a condições semiológicas (espaço externointerno), de modo a atenderem às referidas especificidades comerciais, o que equivale a produzir discursos adequadamente sedutores ao público-alvo (CHARAUDEAU, 2010b, p. 24). Assim, de acordo com esse segundo espaço, deve-se pensar o "como fazer" para atender tal ou qual intencionalidade.

O lugar das condições de recepção também se estrutura em dois espaços: o interno-externo, onde se encontra o destinatário ideal, público idealizado pela instância de produção e que ela espera corresponder à construção da imagem dele feita. Já o espaço externo é o lugar do destinatário real, o público consumidor do produto midiático, em nosso caso, da notícia de jornal, que interpreta a informação segundo as condições que lhe são acessíveis (CHARAUDEAU, 2010b, p. 26).

Dito isto, a produção de discursos noticiosos, "sedutores", nos termos de Amaral (2006), que se vincula a necessidades mercadológicas através do projeto de dizer de conotação humorístico-satírica do jornal Meia Hora, passa pela seleção do que deve ou não ser noticiado e como o será. É o que abordaremos na seção seguinte.

\section{OS VALORES-NOTÍCIA NO JORNALISMO POPULAR}

Partindo do pressuposto de que "todos são feitos para o mercado", Amaral (2006, p. 51) discute as principais diferenças entre os jornais conhecidos como de "referência" e aqueles conhecidos como "populares". Além disso, trata das diversas necessidades de cada público-alvo e da influência delas na constituição do jornal. Assim, classificar um jornal como popular não envolve somente uma explicação com base na economia, mas inclui uma percepção cultural relevante para a compreensão adequada do fenômeno sob foco.

É importante evidenciar a necessidade de adequação do jornal ao seu público (leitores, anunciantes), porque decorre daí o privilégio de um ou outro comportamento por parte do jornal. Como diz Amaral (2006, p. 52), alguns jornais se voltam para um público com hábito regular de leitura, interessado em "ler o que ocorre no mundo", já outros se dirigem a camadas mais amplas da população, oferecendo informações mais ligadas ao cotidiano popular, à prestação de serviços e ao entretenimento. Eles focalizam o "mundo do leitor". Segundo a autora (2006, p. 52, grifos seus),

\footnotetext{
O jornalismo praticado no segmento popular da grande imprensa subverte essa lógica de priorizar o "interesse público". Baseia-se no entretenimento e não na informação, mistura gêneros, utiliza fontes populares e muitas vezes trata a informação de um ponto de vista tão particular e individual que, mesmo dizendo respeito a grande parte da sociedade, sua relevância se evapora. Muitas vezes, o interesse do público suplanta o interesse público não em função da temática da notícia, mas pela forma como ela é editada, com base na individuação do problema, o que dá a sensação de não realização do jornalismo.
} 
Desta forma, como se tem enfatizado, os jornais populares seguem a tendência de destacar notícias que interferem no cotidiano dos leitores, que possuam uma característica dramática ou até mesmo humorística.

Para se tornar notícia, um fato necessita de certos requisitos, os chamados valoresnotícia, que correspondem a determinadas qualidades que podem alçá-lo à qualidade de notícia. Amaral (2006, p. 63) relaciona alguns valores-notícia fundamentais para os jornais de referência e para os jornais populares:

a) Para a imprensa de referência, um acontecimento terá mais chance de ser noticiado quando:

- os indivíduos envolvidos forem importantes;

- tiver impacto sobre a nação;

- envolver muitas pessoas;

- gerar importantes desdobramentos;

- for relacionado a políticas públicas;

- puder ser divulgado com exclusividade.

b) Para a imprensa popular, esta chance será maior se:

- possuir capacidade de entretenimento;

- for próximo geográfica ou culturalmente do leitor;

- puder ser simplificado;

- puder ser narrado dramaticamente;

- tiver identificação dos personagens com os leitores (personalização);

- for útil.

Em qualquer dos segmentos, esses valores não precisam ocorrer simultaneamente, entretanto, quanto mais valores um fato comportar, tanto mais qualificado como notícia ele será.

Em relação ao segmento popular, Amaral (2006, grifos nossos) hierarquiza esses valores e destaca como sendo mais importantes "o entretenimento, a utilidade e a proximidade".

$O$ entretenimento, por vezes, decorre de o jornal avaliar o público como consumidor de distração e prazer, por isso este conceito está intimamente relacionado à sensação e à emoção. Cenas julgadas como escandalosas, ridículas ou insólitas são concebidas como passíveis de causar interesse no leitor. Conforme Amaral (2006, p. 64), são pelo menos quatro categorias que compõem a capacidade de entretenimento de uma notícia:

a) Histórias de gente comum encontrada em situações insólitas ou histórias de homens públicos surpreendidos no dia a dia da sua vida privada, como respectivamente podemos demonstrar com estes dois exemplos: Perereca venenosa (Meia Hora, 12/04/2011), caso em que uma esposa passou produto tóxico na genitália para envenenar o marido no ato sexual, ou Lula pressentiu que tinha câncer (Meia Hora, 03/11/2011). 
b) Histórias em que se verifica uma inversão de papéis, por exemplo, Presos policiais de UPP (Meia Hora, 07/09/2011).

c) Histórias de interesse humano, Coisa ruim mata criança a facadas (Meia Hora, 29/07/2012).

d) Histórias de feitos excepcionais ou heroicos, Polícia desce do céu e põe dois na tranca (Meia Hora, 07/06/2012), caso em que uma equipe de policiais, que voava em um helicóptero a $200 \mathrm{~m}$ de altura, avista um assalto na praia, pousa e prende os assaltantes.

A utilidade compreende matérias que ofereçam algum tipo de informação assistencial ao leitor, referindo-se a questões de saúde, segurança, educação, economia, trabalho, etc. Este valor-notícia está ligado, na opinião de Amaral (2006, p. 69), à função que cada vez mais a mídia adota para ela de dizer aos indivíduos como devem viver, serem bons pais, amantes e profissionais. O jornal, nesse caso, torna-se imprescindível à vida das pessoas. Veja-se, pela observação do antetítulo e do título, o caso desta notícia:

Cuidado!

Bin Laden 'leva' vírus para o PC (Meia Hora, 05/05/2011)

O seu assunto trata de uma estratégia de hackers que enviam mensagens por email prometendo imagens de Bin Laden morto. Esses e-mails, ao serem abertos, infectam o computador com um vírus e o deixa vulnerável à ação dos criminosos.

A proximidade envolve uma retórica que busca autenticar o caráter popular do jornal. Sob essa ótica, o fato deve ser narrado de maneira que aproxime o leitor. Amaral (2006) classifica a proximidade em três categorias: ela pode se dar pelo conteúdo do fato, pelas personagens que envolve e pela linguagem utilizada.

Com relação ao conteúdo, são de interesse das classes de menor prestígio econômico especialmente os temas relacionados a trabalho, segurança pública, televisão, futebol e matérias de interesse humano que apresentam dramas cotidianos do povo, além daquelas que privilegiam o espaço local, e não o nacional (AMARAL, 2006). São exemplos as seguintes manchetes, que se referem a comunidades cariocas:

Terror na Vila Kennedy roda com trabucão (05/09/2011)

Sem gás, CV quer 'explodir' Complexo (08/09/2011)

Bonde cai, atinge um poste e deixa 5 mortos (27/08/2011)

Quanto à proximidade pelos personagens, nela é ressaltada a vida do povo. Um fato pode melhor produzir impacto no leitor se for contado por uma pessoa do povo, quando há uma personalização dos problemas e/ou das soluções. Trata-se também de uma questão de representatividade. Esta característica é categorizada por Amaral (2006, p. 65) com o termo "personalização", que assim comenta: 
Personalizar é dar um caráter pessoal, definir um conjunto de parâmetros para que se atenda às exigências de uma pessoa em especial. A personalização pode ser interessante para abrir uma reportagem contando a vida de alguém do povo, por exemplo, mas de forma extremada também pode levar à execração pública de supostos criminosos ou corruptos, prática adotada nos programas dedicados ao jornalismo policial.

Amaral (2006) explica ainda que a adoção de tal estratégia, às vezes, gera uma extrema singularização da notícia, quando o fato diz respeito de modo muito individual a uma personagem, mas não possui um interesse coletivo, como nos seguintes títulos se pode obter uma prévia:

Bilhete incrimina 'chifronésio' (29/07/2012)

Doença faz mandiocão de agricultor crescer sem parar (07/04/2011)

Por outro lado, as falas de testemunho ou opinião de personagens ou de autoridades no assunto tratado que fundamentam as fontes da notícia são constantemente empregadas para dar visibilidade às pessoas do povo e às suas histórias, o que garante popularidade para o jornal. Entretanto, a preferência por fontes populares, em detrimento de fontes oficiais, nem sempre garante o esclarecimento do tema. Em muitos casos, são utilizadas com função testemunhal de situações dramáticas, servindo ao sucesso da publicação.

Assim, a proximidade pela linguagem se dá constantemente pelo uso do discurso direto, que, ao reproduzir a fala do povo e dos personagens diretamente envolvidos, confere credibilidade ao jornal por produzir um efeito de veracidade e seriedade da informação. $\mathrm{O}$ trecho que segue representa um desses casos:

Fui absolvido nos dois casos. Se eu fosse bandido, estava num carro roubado", alegou Léo, que disse trabalhar como feirante e mototaxista há um ano e meio, e estava em Zafira que pertence ao cunhado. (Terror roda com trabucão na Vila Kennedy, Meia Hora, 05/09/2011.)

O sentimento de proximidade pode ser obtido pelo jornal, ainda, ao introduzir o leitor no enunciado, como o subtítulo Tá com inveja? Pois saiba que ele quer ajuda do SUS para fazer cirurgia e acabar com o bonde do bilau sem freio (Doença faz mandiocão de agricultor crescer sem parar, Meia Hora, 07/04/2011), no qual outro recurso de linguagem é também aplicado: o uso de vocabulário já conhecido pelo leitor, como "bonde", na acepção de "grupo" ou, como foi apresentado há pouco, "trabucão", na acepção de "armamento pesado".

Assim, muitas vezes, no jornal, algumas notícias são tratadas pelo filtro de mais de uma dessas categorias. Como se poderá observar, Papa pede pra sair comporta valores tanto de entretenimento (decorrente de um estranhamento pela associação de universos distintos) como de proximidade (pela associação do assunto noticiado a outro familiar ao universo do leitor). Nos dois casos, a intertextualidade exerce papel fundamental na produção dos sentidos pretendidos e a colocação em cena desse dispositivo pode, paralelamente, orientar a interpretação do texto. 
A noção de intertextualidade foi introduzida por Kristeva (1974[1969]) para discutir o procedimento de redistribuição de um texto em outros na literatura. Segundo ela, "Qualquer texto se constrói como um mosaico de citações e é a absorção e transformação de outro texto.” (p. 60).

Vários autores, em diversos quadros teóricos (estudos literários, pragmática, análise do discurso, linguística textual), trataram da interação estabelecida entre textos no processo de produção e de recepção.

Em Análise do discurso, por exemplo, Charaudeau e Maingueneau (2004, p. 288, grifos dos autores) explicam que "o termo designa ao mesmo tempo uma propriedade constitutiva de qualquer texto e o conjunto das relações explícitas ou implícitas que um texto ou um grupo de textos determinado mantém com outros textos". Maingueneau (1984, p. 83) reserva para o termo "intertexto" a porção textual citada, aludida, parafraseada etc. em outro texto. Já a "intertextualidade", para o autor, corresponde às regras de inserção desse intertexto, que podem tanto compreender o discurso em uma determinada formação discursiva, quanto o gênero discursivo.

Em Linguística Textual, Beaugrande e Dressler (1981), citados por Koch (2003, p. 59), apresentam sete critérios de textualidade (coerência, coesão, intencionalidade, aceitabilidade, situacionalidade, informatividade e intertextualidade), que são um conjunto de princípios constitutivos de todos os textos, dependentes, sobretudo, do conhecimento linguístico das pessoas. Desenvolvendo seus estudos no interior deste quadro, Koch (2003, p. 59), voltando-se para a produção de sentidos na constituição dos textos, distingue intertextualidade em sentido amplo e em sentido restrito. Abarca, dessa forma, aquelas interpretações direcionadas ao estudo do discurso e outras que primam pelo estudo da textualidade. Trata em separado a noção de polifonia, fenômeno mais amplo que, até certo ponto, possui noção recíproca à de intertextualidade, mas incorpora casos fora do escopo desta última.

Essa relação é considerada como restrita quando acontece entre textos efetivamente realizados. Nesse sentido, as citações, alusões a outro texto, bem como a retomada de estilos/escolas literárias constituem esse tipo de intertextualidade. Isto pode ocorrer de forma explícita, se há, por exemplo, citação do texto fonte ou de forma implícita; se não há, como em alguns tipos de paráfrase e ironia. A intertextualidade em sentido amplo corresponderia à ideia de "interdiscursividade", grosso modo, entrelaçamento de vários discursos, noção fundamental nos estudos em Análise do discurso, tal como preconizados em Pêcheux (1983).

Também Authier-Revuz (1998) trabalhara com essa distinção ao discutir a heterogeneidade do sujeito, que foi subdividida pela autora em duas partes: a constitutiva, na qual postula que todo discurso resulta do entrelaçamento de diferentes discursos, e a mostrada, que se refere às formas marcadas desses entrelaçamentos (discurso direto, uso de aspas, etc.)

Bakhtin (2003, p. 292) nos explica que quando tomamos uma palavra e a enunciamos, não o fazemos tomando-a sempre do sistema da língua, em sua forma 
neutra. Fazemos isto a partir de outros enunciados e, antes de tudo, congêneres ao nosso (pelo tema, composição, estilo). Como diz o autor (2003, p. 293), "as palavras podem entrar no nosso discurso a partir de enunciações individuais alheias, mantendo em menor ou maior grau os tons e ecos dessas enunciações individuais".

Esse contato com o enunciado do outro adquire novos matizes na situação concreta. Para Bakhtin (2003, p. 294), pode-se dizer que qualquer enunciado existe para o falante em três aspectos: como unidade do sistema; como unidade alheia, cheia de ecos de outros enunciados; e, por último, como unidade do próprio enunciador, que o incorpora como sua no momento da enunciação. Ele explica ainda que as experiências individuais de qualquer um se desenvolvem em interação constante e contínua com os enunciados individuais dos outros, que trazem em si seu tom valorativo e são assimilados, reelaborados e reacentuados.

Por fim, Koch e Elias (2008, p. 78), acerca da interpretação, asseveram que, por outro lado, a produção do novo texto conterá ecos do texto-fonte, que se farão ouvir (ou não) dependendo dos conhecimentos do leitor. Quer dizer, a ativação do texto-fonte, o seu reconhecimento, é condição necessária para a construção de sentidos.

\section{RELAÇÕES INTERTEXTUAIS NA ELABORAÇÃO DE TÍTULOS DO JORNAL MEIA HORA 5.1 CONTEXTUALIZAÇÃO}

Terça-feira de Carnaval, dia 12/02/2013. Em todo o país, as atenções estão voltadas para a festividade popular. No Rio de Janeiro, os blocos e o desfile das escolas de samba recebem a maior parte da atenção das mídias. Em meio a esta efervescência pagã, a tudo o quanto noticiar, um acontecimento divide com o Carnaval as principais páginas dos jornais: o Papa Bento XVI anuncia a sua renúncia ao cargo mais alto da Igreja Católica.

No mundo, alguns dos principais jornais transformam este acontecimento em notícia e a ele dedicam as suas capas:

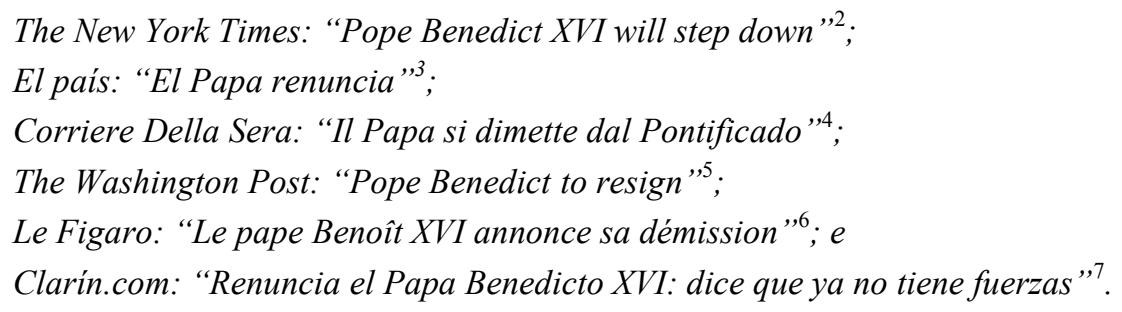

\footnotetext{
2 Papa Bento XVI vai deixar o cargo.

${ }^{3}$ Papa renuncia.

${ }^{4}$ Papa se demite do pontificado.

${ }^{5}$ Papa Bento se demite.

${ }^{6}$ Papa Bento XVI anuncia sua renúncia.

${ }^{7}$ Papa Bento XVI renuncia: diz que já não tem forças.
} 
No Brasil, onde não foi diferente, nos grandes jornais surgiram as seguintes manchetes:

\author{
O Globo: O sagrado: "Trono vazio no Vaticano"; \\ O Estado de S.Paulo: "Fragilizado, Bento XVI surpreende e renuncia"; \\ Correio Brasiliense: "Renúncia do Papa expõe dilema da Igreja Católica"; \\ Estado de Minas: "11 de fevereiro, dia de Nossa Senhora de Lourdes - Padroeira dos \\ enfermos - Papa Bento XVI renuncia"; \\ Jornal do Commércio: "Papa renuncia"; e \\ Zero Hora: "Já não tenho forças".
}

No segmento popular, no Rio de Janeiro, o jornal Meia Hora, famoso por suas capas irreverentes, apresenta a manchete "O Papa que nos perdoe... mas é Carnaval!", complementada pelo subtítulo "No dia em que Sua Santidade deixou o cargo, um timaço de mulheres lindas cruzou a Sapucaí. Com todo respeito a Bento 16, o Meia Hora mostra as beldades da folia", dando, assim, relevo à cobertura da festa no Rio.

A relevância dada ao Carnaval, sobretudo pelo recorte adotado no tema, reflete a projeção do público-alvo feita pelo jornal e reafirma a importância atribuída ao local em detrimento do global, bem como a temas mais próximos do mundo real do leitor, características do segmento popular (AMARAL, 2006) e do contrato de comunicação (CHARAUDEAU, 1996) em que se inserem as instâncias de produção e de recepção. Dessa forma, já na página 24, ressalvada a ordem de importância operada na capa do jornal, o acontecimento é noticiado como segue:

\title{
PAPA BENTO 16 PEDE PRA SAIR \\ Joseph Ratzinger, aos 85 anos, surpreende o mundo todo
}

\begin{abstract}
Em decisão surpreendente para 1,1 bilhão de católicos em todo o mundo, o Papa Bento 16 anunciou ontem que deixará a liderança da Igreja Católica no próximo dia 28. O Pontífice, de 85 anos, justificou a renúncia dizendo, em latim, que está muito velho para continuar a comandar "a barca de São Pedro e levar o Evangelho".

Em seu pronunciamento, numa reunião de cardeais para anunciar canonizações, Joseph Ratzinger disse: "Depois de examinar a minha consciência ante Deus, tive a certeza de que a minha fortaleza, devido à minha idade avançada, não é adequada para o exercício do ministério que foi confiado a mim". O último a renunciar ao cargo foi Gregório XII, em 1415.

Após o anúncio, Bento 16 retirou-se para sua residência de verão. Com a escolha do novo Papa, ele deve passar a morar num mosteiro de clausura no próprio Vaticano. O próximo Papa será eleito num conclave até o fim de março. Há pelo menos cinco brasileiros incluídos nas listas dos mais cotados.

Há quem afirme que a decisão não foi recente. Giovanni Maria Vian, diretor do L'Osservatore Romano, jornal oficial do Vaticano, disse que a medida foi tomada na viagem dele ao México e a Cuba, em março de 2012.

Em nota oficial, a Conferência Nacional dos Bispos do Brasil (CNBB) informou que a entidade recebeu "com surpresa" o anúncio do papa, mas acolheu "com amor filial as razões apresentadas por Sua Santidade, sinal de sua humildade e grandeza".
\end{abstract}


Como se pode atestar diariamente, o jornal Meia Hora não se caracteriza por uma tendência de apresentar os fatos opinativamente como é mais comum nos jornais de referência. Suas notícias tendem a ser linguisticamente organizadas mais em construções narrativas e expositivas, e menos em argumentativas, característica, dentre outras, dos jornais ditos populares (AMARAL, 2006). Entretanto, isto não significa que o jornal se ausente totalmente quanto a posicionar-se diante de um acontecimento.

Se, por um lado, nesse jornal, o corpo do texto da notícia não apresenta comumente um recorte opinativo que conduza o leitor, por outro, é possível ser no título que isto "clandestinamente" ocorra, o que talvez configure, então, um estilo do jornal.

Interessa-nos, sobremaneira, observar o recurso de construção de sentidos adotado no título, que a nosso ver, por hipótese, exemplificaria como, a partir da construção de um título, pode-se sugerir ao leitor um julgamento do fato sobre o qual seria comum o jornal titular apenas sobrepondo alguns efeitos estilísticos, como lhe é característico.

Assim, no caso em tela, é o estabelecimento de uma relação intertextual a partir do título com o filme Tropa de Elite ${ }^{8}$ que constrói uma orientação argumentativa direcionando o modo de o leitor interpretar a notícia. Verón (2004, p. 134) explica que a operação intertextual pode permanecer nos limites de um mesmo campo semântico, como o cinema, a política; ou pode envolver uma transferência entre campos semânticos heterogêneos, p. ex., do teatro à política, etc.

Nessa transferência, o enunciado Papa Bento 16 pede pra sair evoca a situação discursiva do filme, traz consigo os ecos daquela enunciação (BAKHTIN, 2003), na qual a fala do Capitão Nascimento (interpretado pelo ator Wagner Moura) "Pede pra sair" é repetida várias vezes, ordenando que os recrutas designados por $01,02 \ldots$ etc. (diga-se, anônimos, sem dignidade) desistam e renunciem ao curso de formação de soldados do BOPE (Batalhão de Operações Especiais).

Comutativamente, "pede pra sair" pode ser substituído, em primeira instância, por "renuncia". No entanto, considerada uma leitura mais profunda e destacado o aspecto argumentativo do título, nele pode-se remontar ao sentido atribuído no filme, ou seja, "desiste", "acovarda-se" ou então, por último, "cede à pressão", que a enunciação efetiva, a realização do título, pode sugerir como imposição pela insatisfação por parte de alguma instância interior à Igreja ou exterior a ela, como a opinião pública, a dos fiéis. Assim, de forma similar, paradigmaticamente, "Papa Bento 16" poderia ser substituído por $01,02 \ldots$, etc.

Quer dizer, num primeiro momento, aparentemente o título nos parece inocente, mas quando encarado por uma perspectiva intertextual, pode sugerir vinculações a outros discursos em voga na agenda política internacional que envolvem a Igreja

\footnotetext{
${ }^{8}$ O Filme de 2007, dirigido por José Padilha, alcançou enorme bilheteria e deu origem a Tropa de Elite II, a maior bilheteria da história do cinema nacional.
} 
Católica (por extensão, o seu dirigente) e que se circunscrevem em torno de assuntos como uso de preservativos e legalização do casamento entre homossexuais, entre outros, questionando o papel da Igreja no mundo atual. Ademais, não obstante os temas que se lhe apresentam como desafio, a Igreja enfrenta ainda problemas internos, como casos de pedofilia envolvendo seus membros e vazamento de documentos confidenciais, situações veiculadas nas várias mídias.

Evidentemente, não podemos desconsiderar o fato de que o reconhecimento de uma relação intertextual na atividade de processamento do texto e de posterior atribuição de coerência a ele dependa do conhecimento de cada leitor, da ativação do texto-fonte na sua memória discursiva, o que, também por hipótese, pode não ocorrer.

Embora isto seja possível, cabe refletirmos sobre a forte presença do intertexto com o qual se vincula a notícia, um filme assistido por uma enorme quantidade de pessoas e que aborda, entre outros temas, a violência na cidade do Rio de Janeiro, principalmente nas favelas, temática que não passa despercebida aos olhos do leitor, por se referir diretamente ao cotidiano de boa parte deste público consumidor do jornal em questão.

Considerada a possibilidade de ativação do intertexto e os possíveis sentidos dela decorrentes, projetamos nossa reflexão sobre outros aspectos quanto ao recurso adotado.

Conforme resultados de pesquisa desenvolvida (COSTA, 2013), observamos em títulos do jornal Meia Hora o emprego de diversos recursos linguísticos (estilísticos ou não), com contornos humorísticos e satíricos, que, por vezes, desviam/distanciam o título do assunto a ser noticiado. Por esta razão, justificamos tal peculiaridade como um recurso de captação do leitorado. Identificamos, na notícia sob foco, na construção do seu título, também um movimento nesta mesma direção, com a diferença de que nela assunto e título estão em acordo.

O título, paralelamente, seria o espaço reservado pelo jornal para, de forma atraente, sugerir alguma opinião (quando conveniente), em vez de desenvolvê-la de maneira longa no decorrer do texto, o que poderia infringir o contrato de comunicação entre jornal e leitor desse segmento. Dessa forma, via corpo do texto, o leitor poderia reunir informações acerca do fato, no entanto filtradas pela subjetividade do redator. Em razão disto, a intertextualidade seria estratégia cognitiva eficaz.

Assim, o intertexto teria esta dupla função: atender a uma necessidade mercadológica de captação do leitor (pelo nível de linguagem, pela associação estabelecida) e carrear no título um conteúdo argumentativo não desenvolvido pelo corpo do texto da notícia - mais expositivo.

\section{CONSIDERAÇÕES FINAIS}

O uso do intertexto "pede pra sair" revela, assim, o ponto de vista pelo qual o fato foi enunciado e, antes, como foi apreendido pelo sujeito comunicante. Trata-se de um dizer implícito capaz de economicamente superpor ou perpassar um conteúdo valorativo à notícia, que pode ser "captado" pelo leitor como sentido, mas talvez não ser reconhecido como recurso na superfície (palpável) do texto. 
Na observação dessa ocorrência, ressalte-se que o uso de um intertexto, bem como o sentido a partir dele almejado, não pode prescindir da reflexão sobre a sua propriedade/impropriedade ao leitor, pois um cálculo mal realizado sobre as possibilidades de processamento pelo grupo a que se destina o texto pode fazer fracassar o ato de comunicação. Esta projeção que a instância de produção executa sobre o público-alvo precisa considerar a aludida possibilidade de atingir o leitor-efetivo para, então, obter os efeitos pretendidos.

Assim, pautamo-nos na operação de intertextualidade tanto restrita (pela presença da fala da personagem Capitão Nascimento, que constitui o intertexto propriamente dito, mesmo sem o auxílio de aspas, o que demonstra a atualidade do texto-fonte na memória discursiva dos espectadores do filme, do redator e leitores do jornal) quanto ampla (pelo entrelaçamento de discursos outros, sobretudo no âmbito da política, da religião na edificação dos sentidos do texto). Cremos que a partir de então foi possível demonstrar que a ativação do intertexto pelo leitor pode implicar diversos sentidos dele decorrentes, tal como relacionar, por exemplo, a renúncia do Papa a uma suposta crise na sua gestão.

Por fim, além disso, acerca de a estratégia ser localizada no título, concluímos que o intertexto é uma estratégia cognitiva eficaz mobilizada intencionalmente para evitar que ocorra no corpo do texto uma argumentação evidente e, talvez, longa, o que infringiria o contrato de comunicação entre jornal e leitor desse segmento.

\section{REFERÊNCIAS}

AMARAL, M. F. Jornalismo popular. São Paulo: Contexto, 2006.

AUTHIER-REVUZ, J. Palavras incertas - as não-coincidências do dizer. Campinas: EDUNICAMP, 1998.

BAKHTIN, M. Estética da criação verbal. 4. ed. São Paulo: Martins Fontes, 2003.

BEAUGRANDE, R. de; DRESSLER, W. Einführung in die Textlinguistik. Tübingen: Niemeyer, 1981.

CHARAUDEAU, P. Para uma nova análise do discurso. Tradução de Agostinho Dias Carneiro. In: CARNEIRO, A. D. (Org). O discurso da mídia. Rio de Janeiro: Oficina do autor, 1996. p. 5-43.

Uma teoria dos sujeitos da linguagem. In. MARI, H, et alii. Análise do discurso: fundamentos e

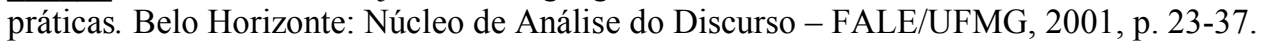

Identité sociale et identité discursive, le fondement de la compétence communicationnelle.

Gragoatá, Niterói, n. 21, p. 339-354, jul./dez. 2006.

. Linguagem e discurso: modos de organização. 2. ed. São Paulo: Contexto, 2010a.

Discurso das mídias. 2. ed. São Paulo: Contexto, 2010b.

; MAINGUENEAU, D. Intertextualidade. In: CHARAUDEAU. P; MAINGUENEAU, D. Dicionário de Análise do discurso. São Paulo: Contexto, 2004. p. 288.

COSTA, W.A.S. Do título ao texto/ Do texto ao título: o processo de estabilização da referência em notícias do jornal Meia Hora. 2013. 212f. Tese (Doutorado em Estudos de Linguagem) - Programa de Pós-graduação em Estudos da Linguagem, Universidade Federal Fluminense, Niterói, 2013.

FOLHA DE S.PAULO. Manual de estilo. São Paulo: FSP, 2001.

KOCH, I. O texto e a construção dos sentidos. 7. ed. São Paulo: Contexto, 2003.

KOCH, I; ELIAS, V. Ler e compreender: os sentidos do texto. 2. ed. São Paulo: Contexto, 2008.

KRISTEVA, J. Introdução à semanálise. São Paulo: Perspectiva, 1974[1969].

MAINGUENEAU, D. Genèses du discours. Liège: Mardaga, 1984. 
PÊCHEUX, M. A Análise de Discurso: Três épocas (1983). In: GADET, F.; HAK, T. Por uma Análise Automática do Discurso: Uma introdução à obra de Michel Pêcheux. Campinas: EDUNICAMP, 1990. p. 311-319.

VERÓN, E. Fragmentos de um tecido. São Leopoldo: Editora Unisinos, 2004.

Recebido em: 23/03/13. Aprovado em: 30/11/13.

Title: Intertextual operations in the title category in the Rio de Janeiro newspaper Meia Hora

Authors: Vanda Cardozo de Menezes; Wagner Alexandre dos Santos Costa

Abstract: In order to demonstrate that in popular newspapers news can also be pervaded by an opinion, but from unconventional strategies, this article will analyze the construction of the title "Pope asks to quit", the news published in the popular carioca newspaper Meia Hora on 12/02/2013. Our focus is on how the establishing of an intertextual relationship in the title adds and directs senses of the text in an argumentative mode. One of our conclusions is that the title would be the placeholder for the newspaper to suggest an opinion rather than develop it throughout the text, a strategy that could violate the contract of communication between newspaper and reader of this segment. Our theoretical frame includes the notion of "communication contract" developed in discourse analysis (Charaudeau, 1996; 2001); the characterization of "news-values" (Amaral, 2006); and in "intertextuality" (BEAUGRANDE \& DRESSLER (1981); BAKHTIN (2003), Koch (2003), among others) process.

Keywords: Popular journalism. Intertextuality. Construction of meaning.

Título: Operaciones intertextuales en la categoría título en el periódico carioca Meia Hora Autores: Vanda Cardozo de Menezes; Wagner Alexandre dos Santos Costa

Resumen: Con la intención de demostrar que en los periódicos populares la noticia también puede ser permeada por una opinión, sin embargo, desde estrategias no convencionales, en este artículo será analizada la construcción del título "Papa pide a salir", de noticia publicada en el periódico popular carioca Meia Hora, a 12/02/2013. Nuestra preocupación se concentra en la reflexión de como el establecimiento de una relación intertextual, ya en el titulo, puede añadir sentidos y orientar el texto de manera argumentativa. Una de nuestras conclusiones es que el título sería el espacio reservado por el periódico para sugerir alguna opinión, en lugar de desarrollarla de manera larga en el curso del texto, lo que podría infringir el contracto de comunicación entre periódico y lector de ese segmento. Como aparato teórico, nos guiamos en la noción de "contracto de comunicación", desarrollada en el Análisis del discurso (CHARAUDEAU, 1996; 2001); en la caracterización de los "valores-noticia" (AMARAL, 2006); y en el proceso de "intertextualidad" (BEAUGRANDE; DRESSLER (1981); BAKHTIN (2003); KOCH (2003), entre otros.

Palabras-clave: Periodismo popular. Intertextualidad. Construcción del sentido.

MENEZES, Vanda Cardozo de; COSTA, Wagner Alexandre dos Santos. Operações intertextuais na categoria Título no jornal carioca Meia Hora. Linguagem em (Dis)curso - LemD, Tubarão, SC, v. 14, n. 2, p. 233-246, maio/ago. 2014. 